\title{
Efficacy of the Health Belief Model for Predicting Intention to Pursue Genetic Testing for Colorectal Cancer
}

\author{
Amanda Cyr • Tim Allen Dunnagan • George Haynes
}

Received: 4 August 2008 /Accepted: 22 October 2009/Published online: 10 November 2009

(C) National Society of Genetic Counselors, Inc. 2009

\begin{abstract}
This study examined the Health Belief Model's efficacy to predict intention to undergo genetic testing for the Colorectal Carcinoma (CRC) gene within a rural/ frontier setting. Survey data were collected on 558 Southwest Montanan residents. Regression analysis revealed that perceived benefits, including affordability and satisfying curiosity, were the strongest indicators of intention to undergo genetic testing for CRC. Select consumer barriers and cues to action variables were also found to be significant predictors. Collectively the model explained approximately $36 \%$ of the variance. These preliminary findings have implications for genetic counselors, health practitioners and health care providers concerned with genetic counseling and addressing the public health issue of CRC.
\end{abstract}

Keywords Colorectal cancer screening $\cdot$ Predicting genetic testing $\cdot$ Health belief model

\footnotetext{
A. $\mathrm{Cyr}$

Health Management Research Center, University of Michigan, 1015 E Huron,

Ann Arbor, MI 48104-1689, USA

T. A. Dunnagan $(\bowtie)$

Health and Human Development,

Montana State University-Bozeman,

219 Herrick Hall, P.O. Box 173540, Bozeman, MT 59715, USA

e-mail: dunnagan@montana.edu

\section{G. Haynes}

Economics and Agricultural Economics,

Montana State University-Bozeman,

210-E Linfield Hall, P.O. Box 173540,

Bozeman, MT 59715, USA

\section{Introduction}

Cancer is the second leading cause of death in the United States; in 2006 cancer accounted for one in every four deaths (American Cancer Society 2006). The direct and indirect costs of cancer are estimated to be 200 billion dollars per year. Therefore, cancer is a significant health issue and needs to be addressed. Colorectal Carcinoma (CRC) is the third most common cancer found in men and women in this country. The American Cancer Society estimated that there would be about 106,680 new cases of colon cancer and 41,930 new cases of rectal cancer in 2006 in the United States. Combined, these cancers were expected to account for approximately 55,170 deaths.

Genetic testing, if used, has the potential to enhance individual health and well-being (U.S. Department of Health and Human Services and National Cancer Institute 2007). Some tests are used to clarify a diagnosis and direct a physician toward appropriate treatments. Genetic tests can also be used to identify individuals who are at risk for preventable diseases. Finally, genetic testing can be used as a powerful diagnostic tool that has many benefits to the consumer. For example, if an individual tests positive for a gene mutation, enhanced screening protocols can be initiated so that tumors can be identified early in their development, and thus increase one's chances for survival. Applications such as this could potentially prevent thousands of cancer deaths a year. However, consumers' decisions to be tested are idiosyncratic and difficult to understand. If health care providers are to help clients make informed decisions about testing, they need insight into the factors that are important to their client's decision making process. Consequently, explanatory theories need to be devised and evaluated to understand the idiosyncratic processes associated with 
the decision to be tested for gene mutations associated with conditions such as CRC. The purpose of this study was to examine the efficacy of the Health Belief Model (HBM) to predict intention to undergo genetic testing for the gene mutations associated with CRC within a rural/ frontier setting.

\section{Background}

The public health burden of colorectal cancer is substantial (American Cancer Society 2006; Bunn et al. 2002). Twenty-five percent of individuals who have a family history of CRC also have a genetic mutation. While the actual proportion of individuals who have CRC due to genetic mutations is low, genetic mutations have been identified as a cause of inherited CRC risk. Knowledge about cancer genetics is rapidly expanding, with implications for all aspects of cancer management, including prevention, testing, and treatment.

\section{Genetic Causes of Colon and Rectal Cancer}

Genes associated with a higher risk of CRC are rare. However, these inherited gene alterations can increase a carrier's risk of acquiring CRC by as much as $90 \%$. The two main genetic syndromes that have been isolated for CRC are FAP and HNPCC (Frank et al. 2004 ; Ho et al. 2003). The adenomatous polyposis coli (APC) gene has been linked to familial adenomatous polyposis or more commonly known as FAP (American Cancer Society 2006). The APC gene is normally responsible for slowing down the growth of cells; when there is a change in this gene the outcome is FAP or Gardner syndrome. In addition, a defective DNA repair mechanism gene (i.e., MSH2, MLH1, PMS1, PMS2, MSH3, and MSH6) is responsible for hereditary nonpolyposis CRC (HNPCC). Mutations in the DNA repair enzyme genes in HNPCC allow DNA errors to go uncorrected, and these errors will sometimes affect growth-regulating genes, possibly leading to the development of CRC.

\section{Genetic Testing}

There are potential benefits to genetic testing, whether a person receives a positive or a negative result (U.S. Department of Health and Human Services and National Cancer Institute 2007). As mentioned previously, some tests are used to clarify a diagnosis and direct a physician toward appropriate treatments. Some genetic tests allow families to avoid having children with devastating diseases. Also, tests can be used to identify individuals who are at risk for preventable diseases. In short, genetic testing, if used properly could be a powerful diagnostic tool with potential implications for both symptomatic and asymptomatic individuals.

The potential benefits of a negative result include a sense of relief and elimination of the need for special preventive checkups, tests, or surgeries such as annual colonoscopy (a procedure that allows a physician to view the upper reaches of the large intestine), which are routine for high-risk families at risk for CRC (U.S. Department of Health and Human Services and National Cancer Institute 2007). A positive test result can bring relief from uncertainty and allow people to make informed decisions about their future, including taking steps to reduce cancer risk. When colon cancer tumors are found early, chances for survival are greatest, and screening potentially could prevent thousands of cancer deaths. A positive gene test can encourage individuals to maintain regular screening practices (annual colonoscopies to check for precancerous polyps or the earliest signs of cancer) and to maintain healthful lifestyle measures such as a high-fiber, low-fat diet and regular exercise.

One obstacle that genetic counselors and other health professionals face especially with individuals who could potentially benefit from the procedure, is the reluctance of individuals to undergo genetic testing for a predisposition such as CRC (Ramsey et al. 2003). Consumers are influenced by a wide combination of factors that could influence their decision to undergo genetic screening including financial, emotional, familial pressure, religious, social and other motivational concerns. Educating genetic counselors and other health professionals about the cognitive, motivational and emotional factors that influence decision making processes would enable them to better understand their clients and thus be more helpful when they make decisions about testing. In other words, by better understanding what is important to the client, the practitioner can better facilitate more thoughtful decision making on the part of the client.

Therefore, there is an immediate need to find the best predictors of different populations' decisions to undergo genetic testing for health risk factors such as CRC. The Health Belief Model was used in this study in an attempt to better understand the barriers, benefits, and cues to action that clients face when making a decision to undergo genetic testing for the predisposition for CRC.

\section{Health Belief Model}

The Health Belief Model (HBM), displayed in Fig. 1, has been used extensively to predict health behaviors. The model was initially developed to explain the widespread failure of individuals to participate in programs to prevent and detect disease (Strecher and Rosenstock 1997). Over the last fifty years the HBM has been one of the most 
Fig. 1 Health Belief Model (HBM). Note. Figure Taken from Janz et al. (2002, p. 52).
INDIVIDUAL PERCEPTIONS
MODIFYING FACTORS

LIKELIHOOD OF

ACTION

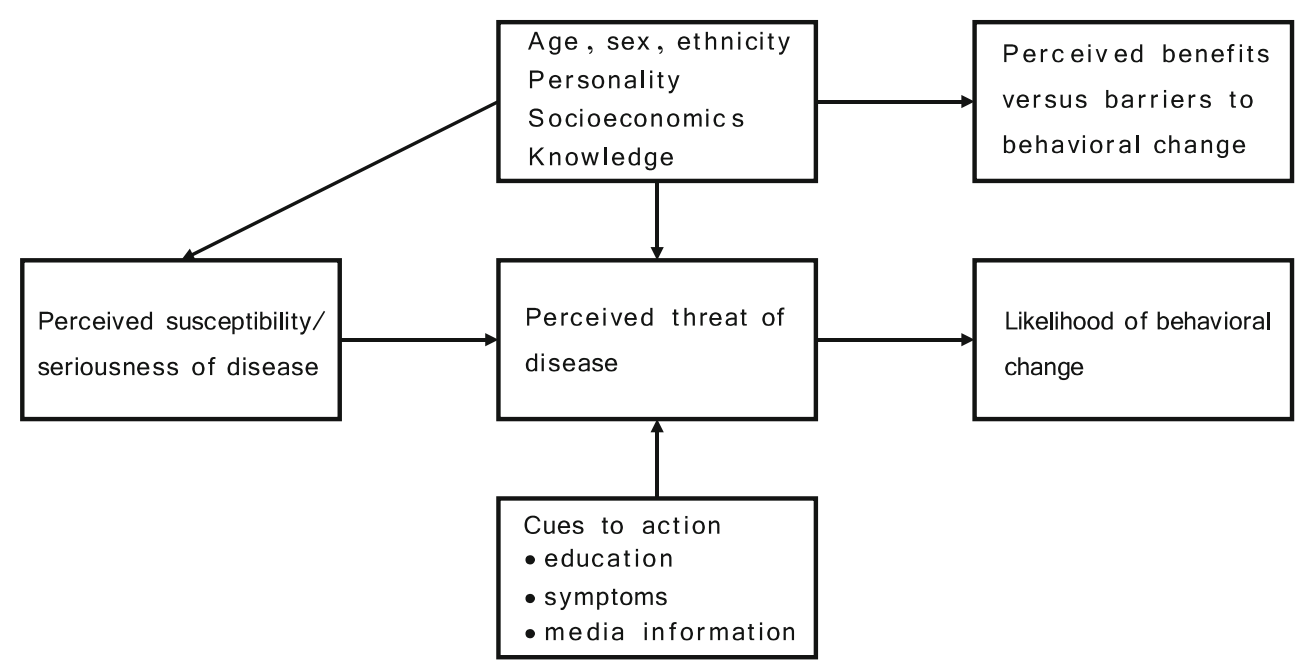

widely used conceptual frameworks to guide health programming and research.

The HBM considers the individual's personal perceptions of susceptibility, seriousness, cues to action, personal demographic variables (gender, age, socioeconomic status, education and knowledge), and benefits and barriers regarding a disease (Fig. 1). Collectively the components may predict an individual's course of action. The components as described by Janz et al. (2002) include: the perceived susceptibility and perceived severity of a disease (together defined as perceived threat), perceived benefits of preventative action, and perceived barriers to a preventative action. Cues to actions can also serve as prompts to engage in a preventive action. Some researchers use all of the components of the HBM while others only use select components of the model that are most relevant to a given intervention. In this study the researchers utilized perceptions of susceptibility, benefits, barriers, cues to action, and select personal demographic variables.

\section{HBM and Genetic Testing for CRC}

The HBM model has been used in the past to predict the decision to take preventative screening actions for individual health (Bunn et al. 2002; Hartman 2002). Some researchers (Bunn et al. 2002; Ho et al. 2003) have recently initiated work using the HBM to predict consumers' intention to undergo a genetic test for CRC. The investigators in both of these studies collected their data within an urban setting. However, no published investigations have used the HBM to explain intention to seek genetic screening for CRC in rural and frontier settings. Individuals in rural and frontier settings are often medically underserved and less research is dedicated to this population when compared to their urban counterparts. Therefore, there is a need for further research to specifically research this underserved population.

\section{Methods}

\section{Overview}

An exploratory investigation was conducted to examine the associations between the intention to engage in genetic testing for CRC (dependent variable) and the independent variables of interest (components of the HBM). The research procedures and methods for collecting data were approved by the Montana State University Human Subjects Committee in October of 2006. Because survey respondents were not identified in the data collection process, the use of an informed consent was not needed. To conduct this investigation the following major steps were initiated:

1. In-depth interviews were conducted on a sample from the target population of Southwest Montana residents to help with the development of the HBM mail-out survey.

2. Based on the interviews and past research, the dependent and independent variable questions were created for the HBM mail-out survey.

3. After the HBM mail-out survey was developed, a piloting process was conducted using concurrent and retrospective interviews.

4. Once finalized, the HBM mail-out surveys were sent via the U.S. Postal Service to 1,120 randomly selected individuals within rural/frontier settings. Of the 1,120 addresses, 1,020 of the addresses were valid and represented the final sample for the mailing. 
5. The returned surveys were entered, cleaned and analyzed using descriptive statistics and regression analysis.

Sample and Procedures

The investigators desired a sample of individuals from rural and frontier settings because the vast majority of Montana counties are rural and frontier. Based on Office of management and Budget criteria, frontier sites are defined as counties that have 6 or fewer individuals per square mile and rural sites are counties with more than six and fewer than fifty individuals per square mile. Urban areas have more than 50 individuals per square mile. Montana has 45 counties classified as frontier, ten as rural, and one as urban. To this end Butte, MT (Silver Bow county) was selected as the rural location and Livingston, MT (Park County) was selected as the frontier location because they were both located in Southwest Montana. Five-hundred-ten surveys were randomly distributed to residents of each county.

The surveys were distributed based on approaches suggested by Dillman (2000). First, a pre-notification letter describing the study was mailed to all recipients selected for the investigation. After correcting for inaccurate addresses obtained through the original mailing list, a survey, cover letter, one dollar incentive and pre-addressed stamped return envelope were mailed to the recipients. The cover letter explained that the survey was being conducted to increase awareness of genetic testing for CRC. In order for the results to be random, we asked that the resident who was at least 18 years of age who permanently lived in the house, and most recently had a birthday, complete the survey. One week after the survey mailing a reminder post card was mailed thanking those who returned the survey and encouraging those who had not to do so as soon as possible.

\section{Instrumentation}

\section{In-Depth Interviews}

In-depth interview questions were designed to gather opinions and beliefs about genetic testing for CRC from a sample of the targeted population of rural and frontier Montanans. The development of these interview questions was informed by the work of Bunn et al. (2002) and Ho et al. (2003). Relevant questions concerning the HBM components from these researchers' surveys were used in the development of interview questions used in this investigation. In short, the components of the HBM (perceived susceptibility, benefits, barriers, and cues to action) guided the creation of open-ended questions (questions that allow for diverse responses) to measure engagement behaviors for genetic testing (Bunn et al. 2002; Hartman 2002; Ho et al. 2003). Hartman (2002) provided a detailed account of her interview questions and procedures for examining breast cancer screenings in rural Montana. Information from this study provided considerable guidance for the research team because of the population and topic similarities.

The interviews were conducted on a convenience sample of 15 Southwest Montana residents after they provided signed consent. Conversational interviewing and probing techniques were used to develop a consistent interaction between the interviewee and interviewer (Babbie 2002). Before initiating the interviews, the first author who has received graduate level training in interviewing techniques, presented basic information about CRC, the gene mutations associated with CRC, and genetic testing (Ramsey et al. 2003). Next, the interviewees were told about the patterns and risks associated with the genetic mutations including both FAP and HNPCC. The open-ended interview questions displayed in Fig. 2 generated feedback about the interviewees' beliefs, attitudes, knowledge, barriers, concerns, and influencing factors related to the issue of having genetic testing for gene mutations associated with CRC.

The interviews were recorded verbatim and content analysis was used to identify the general trends and themes as they related to the HBM. The general trends and themes gathered from these interviews were applied to the development of questions for the HBM mail-out survey. Specifically, the trends and themes were put into categories based on the components of the HBM (Bunn et al. 2002; Hartman 2002; Ho et al. 2003). These categories included overall genetic testing knowledge, benefits, barriers, susceptibility, and cues to action. The results of the in-depth interviews and questions generated through past research contributed to the development of the HBM mail-out survey questions which are described in detail in the following section.

\section{Dependent and Independent Variables}

The dependent and independent variables were created based on the in-depth interviews as well as past research surveys involving the HBM (Bunn et al. 2002; Hartman 2002; Ho et al. 2003). The dependent variable was based on responses to the question, "If genetic testing for cancer risks were available to you now, would you be likely to get tested in the next six months?"

The independent variables of interest included the HBM components and were measured with questions related to perceived susceptibility, benefits, barriers, cues to action, and personal demographics. An example of perceived 
Fig. 2 Questions for In-Depth Interviews.

\begin{tabular}{|c|c|c|}
\hline $\begin{array}{l}\text { Attitudes, Beliefs, and knowledge about } \\
\text { genetic testing }\end{array}$ & $\begin{array}{l}\text { Concerns regarding the barriers } \\
\text { surrounding genetic testing }\end{array}$ & $\begin{array}{c}\text { Factors influencing the } \\
\text { decision }\end{array}$ \\
\hline $\begin{array}{l}\text { 1. When you hear the word genetic testing, } \\
\text { what comes to mind? }\end{array}$ & $\begin{array}{l}\text { 5. How would you rate your } \\
\text { susceptibility to contracting CRC? }\end{array}$ & $\begin{array}{l}\text { 8. Who would influence you } \\
\text { in making the decision to }\end{array}$ \\
\hline $\begin{array}{l}\text { 2. What are the benefits or positive } \\
\text { attributes of having a genetic test for the }\end{array}$ & $\begin{array}{l}\text { What makes you more or less } \\
\text { susceptible? }\end{array}$ & $\begin{array}{l}\text { undergo genetic testing for } \\
\text { CRC? }\end{array}$ \\
\hline gene mutation for CRC? & 6. Has your primary physician ever & 9. What other factors would \\
\hline $\begin{array}{l}\text { 3. What are the barriers or negative } \\
\text { attributes that might be associated with }\end{array}$ & $\begin{array}{l}\text { talked to you about having a genetic } \\
\text { test for CRC or any other cancer? }\end{array}$ & $\begin{array}{l}\text { influence your decision to } \\
\text { undergo genetic testing? }\end{array}$ \\
\hline $\begin{array}{l}\text { having a genetic test for the gene mutation } \\
\text { associated with CRC? }\end{array}$ & $\begin{array}{l}\text { 7. How would you encourage a } \\
\text { family member to be genetically }\end{array}$ & $\begin{array}{l}\text { 10. Is there anything else that } \\
\text { you would like to talk about }\end{array}$ \\
\hline $\begin{array}{l}\text { 4. What is your primary source(s) for } \\
\text { receiving information about medical } \\
\text { decisions? }\end{array}$ & tested for CRC? & related to $\mathrm{CRC}$ ? \\
\hline
\end{tabular}

susceptibility was generated by asking the respondent if s/ he had a blood relative with CRC. An example of perceived benefits was generated by asking the respondent if $\mathrm{s} / \mathrm{he}$ would be tested to satisfy curiosity or to encourage a lifestyle change. Examples of perceived barrier questions included asking the respondents if they would have psychological, emotional or financial concerns associated with CRC testing. Finally, cues to action questioning included items related to the influence a physician or health care provider might have on the respondents' decision to engaging in genetic testing for CRC.

Personal demographic variables addressed current health insurance status, number of dependents, marital status, level of education, income, race, and age. Previous literature has consistently suggested health care and insurance coverage broadly affect the decision to be genetically tested (Bosompra et al. 2000; Church 2006; Keefer 1999; Peterson 2005). Also, personal and demographic variables tend to be strong predictors of health behaviors (Green and Kreuter 1999) and therefore should be included in the analysis.

\section{Survey Pilot}

Prior to piloting the HBM mail-out survey a panel of experts in survey design, genetics and modeling health behaviors reviewed the questions for accuracy, flow, organization and design. Next, the survey was piloted using a convenience sample of ten individuals from a rural Southwest Montana location. To ensure readability and clarity of the survey, both concurrent and retrospective interviewing techniques were used. A concurrent interviewing technique (think-aloud technique) calls for respondents to formulate their thoughts into words while completing the survey. In contrast, a retrospective interviewing technique uses probing questions asked after the respondent has completed the survey (Dillman 2000). The purpose of the pilot for this study was to determine whether the respondents understood the questions, found the layout easy to follow and the delivery of the survey appealing. Survey revisions were made based on the information collected from the pilot participants and the HBM mail-out survey was reviewed again by the same expert panel and finalized prior to distribution.

\section{Survey Construction and Distribution}

The finalized paper and pencil mail-out survey consists of 34 items, divided into two sections: (1) HBM components and (2) personal demographic questions. Most questions use a Likert-type scale, with behavioral anchors such as strongly agree, agree, strongly disagree, disagree, or neither disagree or agree (Babbie 2002). Other questions were structured using yes/no, fill in the blank, or checklists consisting of response categories specific to a given question (e.g., income brackets).

\section{Data Analyses}

Descriptive statistics and regression analysis were used to determine the efficacy of the Health Belief Model as a predictor of intention to undergo genetic testing for CRC. Descriptive statistics were used to describe the characteristics of the sample. Regression analyses were used to identify the best predictors for intention to engage in genetic testing for CRC based on the HBM. Since the 
dependent variable was binary (intention to test or not to test), a logistic regression was conducted. The individual items (questions) associated with each component were coded as a yes/no response so all of these variables were coded as dummy variables. Specifically, on the Likert-scale questions (where the answers were 1=yes, I strongly agree; 2=yes, I agree; 3=no, I disagree; 4=no, I strongly disagree; 5=I neither agree nor disagree; and $6=I$ don't know), 1 and 2 were coded as yes (1) and all other answers were coded as no (0). On the other questions (where the answers were $1=$ yes, $2=$ no, $3=I$ don't know), 1 was coded as yes and all other answers were coded as no. And finally, on the testing question 1 and 2 were coded as yes (1) and all other answers are coded as no (0). Two by two tables were used to report screening behaviors based on key HBM components that were instrumental in determining the decision making process.

\section{Results}

\section{Sample Characteristics}

One thousand twenty surveys were distributed and approximately $55 \%$ of recipients responded $(n=558)$. The respondents were comprised of 219 women and 339 men (Table 1). Ninety-five percent were white, $63 \%$ were married, and slightly over half of the sample had incomes less than $\$ 50 \mathrm{~K}$. Sixty-one percent of the respondents were between the ages of 36 and 64. Sixty-percent had no dependents, $84 \%$ reported having health care coverage, and $31 \%$ had four or more years of college. Overall, $58 \%$ of the respondents indicated they would have a genetic test to detect their cancer risk in the next six months if it was made available to them.

The survey respondents were similar demographically to the populations of Silver Bow and Park Counties with a few exceptions. Specifically, the HBM survey sample was somewhat older and better-educated. The sample had a slightly higher percentage of minority respondents compared to minorities in the Park County population, and a lower percentage of minority respondents compared to minorities in Silver Bow County. The sample had a lower percentage of females than in the population of either Park or Silver Bow counties.

Reponses to Other Survey Items and Reported Likelihood to Pursue Genetic Testing

Table 2 contains a summary of the percentage of respondents who would/would not pursue genetic testing broken down by their responses (yes/no) to survey items concerning the HBM components. For example, under cues to action, the item asking about "prior knowledge of genetic testing" revealed
Table 1 Characteristics of Respondents to the CRC Genetic Testing Survey $(N=558)$

\begin{tabular}{|c|c|c|}
\hline Variable & $n$ & $\%$ \\
\hline \multicolumn{3}{|l|}{ Dependent Variable: } \\
\hline \multicolumn{3}{|c|}{ Likelihood of having genetic test in next six months } \\
\hline Yes & 232 & 41.6 \\
\hline No & 326 & 58.4 \\
\hline \multicolumn{3}{|l|}{ Demographic Variables: } \\
\hline \multicolumn{3}{|l|}{ Ages of respondent } \\
\hline 35 and younger & 49 & 8.8 \\
\hline $36-64$ & 338 & 60.6 \\
\hline 65 and older & 171 & 30.7 \\
\hline \multicolumn{3}{|l|}{ Race of respondent } \\
\hline Minority & 26 & 4.7 \\
\hline Non-minority & 532 & 95.3 \\
\hline \multicolumn{3}{|l|}{ Gender of respondent } \\
\hline Female & 219 & 39.2 \\
\hline Male & 339 & 60.8 \\
\hline \multicolumn{3}{|l|}{ Income } \\
\hline Less than $\$ 10,000-14,999$ & 73 & 13.1 \\
\hline$\$ 15,000-\$ 24,999$ & 80 & 14.3 \\
\hline$\$ 25,000-\$ 49,999$ & 140 & 25.1 \\
\hline$\$ 50,000-\$ 99,999$ & 165 & 29.6 \\
\hline Over $\$ 100,000$ & 100 & 17.9 \\
\hline \multicolumn{3}{|l|}{ Marital Status } \\
\hline Divorced, Separated, Never Married & 207 & 37.1 \\
\hline Married, or coupled & 351 & 62.9 \\
\hline \multicolumn{3}{|l|}{ Number of Dependents } \\
\hline None & 336 & 60.2 \\
\hline 1 or more & 222 & 39.8 \\
\hline \multicolumn{3}{|l|}{ Health Insurance Coverage } \\
\hline Yes & 471 & 84.4 \\
\hline No & 87 & 15.6 \\
\hline \multicolumn{3}{|l|}{ Education Level } \\
\hline Grades $1-8$ (elementary) & 15 & 2.7 \\
\hline Grades 9-11 (some high school) & 29 & 5.2 \\
\hline Grade 12 or GED & 149 & 26.7 \\
\hline College 1-3 years (some college) & 184 & 33.0 \\
\hline College (4 years or more with degree) & 171 & 30.6 \\
\hline
\end{tabular}

that $37 \%(n=51)$ of the 137 respondents who answered "no" indicated that they would not be tested, and $43 \%(n=181)$ of the 421 respondents that answered "yes" indicated they would be genetically tested. For each HBM component item, confidence intervals ( $95 \%$ level of confidence) were examined to determine whether there were statistically significant differences in the percentages of respondents who would pursue genetic versus those who would not pursue testing. In the following sections, only those items found to be statistically significant at a $95 \%$ level of confidence are described. 
Table 2 Comparisons of Responses to HBM Component Items and Reported Likelihood of Pursuing CRC Genetic Testing in the Next Six Months

\begin{tabular}{llllll}
\hline & \multicolumn{3}{l}{ Would test } & & \multicolumn{2}{l}{ Would not test } \\
\cline { 2 - 3 } \cline { 5 - 6 } HBM component items & $n$ & & & $\%$ & $\%$ \\
\hline
\end{tabular}

Prior Knowledge of genetic testing

$\begin{array}{lllll}\text { No }(n=137) & 51 / 137 & 37 & 86 / 137 & 63 \\ \text { Yes }(n=421) & 181 / 421 & 43 & 240 / 421 & 57\end{array}$

Physician or other health care Professional has discussed genetic testing about CRC

$\begin{array}{lllll}\text { No }(n=524) & 215 / 524 & 41 & 309 / 524 & 59 \\ \text { Yes }(n=34) & 11 / 34 & 32 & 23 / 34 & 68\end{array}$

Physician or other health care Professional has discussed early detection for $\mathrm{CRC}^{\mathrm{a}}$

$\begin{array}{lccll}\text { No }(n=214) & 73 / 214 & 34 & 141 / 214 & 66 \\ \text { Yes }(n=344) & 158 / 344 & 46 & 186 / 344 & 54 \\ \text { Have read or heard about genetic testing } & & & \\ \text { No }(n=515) & 211 / 515 & 41 & 304 / 515 & 59 \\ \text { Yes }(n=43) & 19 / 43 & 44 & 24 / 43 & 56\end{array}$

A family member would influence their decision to be genetically tested

$\begin{array}{lllll}\text { No }(n=323) & 136 / 323 & 42 & 187 / 323 & 58 \\ \text { Yes }(n=235) & 94 / 235 & 40 & 141 / 235 & 60\end{array}$

A physician would influence their decision to be genetically tested ${ }^{\mathrm{a}}$

$\begin{array}{lllll}\text { No }(n=58) & 13 / 58 & 22 & 45 / 58 & 78 \\ \text { Yes }(n=500) & 220 / 500 & 44 & 280 / 500 & 56\end{array}$

A health care professional would influence their decision to be genetically tested $^{\mathrm{a}}$

$\begin{array}{lllll}\text { No }(n=227) & 82 / 227 & 36 & 145 / 227 & 64 \\ \text { Yes }(n=331) & 149 / 331 & 45 & 182 / 331 & 55 \\ \text { Perceived Susceptibility } & & & & \\ \text { Blood relative with CRC } & & & & \\ \text { No }(n=475) & 185 / 475 & 39 & 290 / 475 & 61 \\ \text { Yes }(n=81) & 46 / 81 & 57 & 35 / 81 & 43\end{array}$

Likelihood to get CRC in your lifetime ${ }^{a}$

$\begin{array}{lllll}\text { No }(n=535) & 193 / 535 & 36 & 342 / 535 & 64 \\ \text { Yes }(n=23) & 13 / 23 & 57 & 10 / 23 & 43 \\ \text { Nutritional Habits } & & & & \\ \text { No }(n=506) & 202 / 506 & 40 & 304 / 506 & 60 \\ \text { Yes }(n=50) & 26 / 50 & 52 & 24 / 50 & 48 \\ \text { Exercise Habits } & & & & \\ \text { No }(n=514) & 211 / 514 & 41 & 303 / 514 & 59 \\ \text { Yes }(n=40) & 21 / 40 & 53 & 19 / 40 & 47 \\ \text { Smoking Habits }{ }^{\mathrm{a}} & & & & \\ \text { No }(n=513) & 205 / 513 & 40 & 308 / 513 & 60 \\ \text { Yes }(n=39) & 25 / 39 & 64 & 14 / 39 & 36\end{array}$

Perceived Benefits

Family could benefit from the information of a genetic test ${ }^{\mathrm{a}}$

$\begin{array}{lllll}\text { No }(n=169) & 24 / 169 & 14 & 145 / 169 & 86 \\ \text { Yes }(n=389) & 206 / 389 & 53 & 183 / 389 & 47\end{array}$

Table 2 (continued)

\begin{tabular}{llllll}
\hline & \multicolumn{2}{l}{ Would test } & & \multicolumn{2}{l}{ Would not test } \\
\cline { 2 - 3 } \cline { 5 - 6 } HBM component items & $n$ & & & $\%$ & $\%$ \\
\hline
\end{tabular}

Family could make better decision about their own health ${ }^{\mathrm{a}}$

$\begin{array}{lllll}\text { No }(n=147) & 22 / 147 & 15 & 125 / 147 & 85 \\ \text { Yes }(n=411) & 189 / 411 & 46 & 222 / 411 & 54\end{array}$

Could encourage a lifestyle change $\mathrm{a}^{\mathrm{a}}$

\begin{tabular}{|c|c|c|c|}
\hline No $(n=72)$ & $12 / 72$ & 17 & $60 / 72$ \\
\hline Yes $(n=486)$ & $199 / 486$ & 41 & $287 / 486$ \\
\hline \multicolumn{4}{|c|}{ Decrease chance of surgery ${ }^{\mathrm{a}}$} \\
\hline No $(n=331)$ & $106 / 331$ & 32 & $225 / 331$ \\
\hline Yes $(n=227)$ & $125 / 227$ & 55 & $102 / 227$ \\
\hline \multicolumn{4}{|c|}{ Satisfy curiosity ${ }^{\mathrm{a}}$} \\
\hline No $(n=304)$ & $61 / 304$ & 20 & $243 / 304$ \\
\hline Yes $(n=254)$ & $173 / 254$ & 68 & $81 / 254$ \\
\hline
\end{tabular}

Perceived Barriers

Large financial impact on myself or my family ${ }^{\mathrm{a}}$

$\begin{array}{lllll}\text { No }(n=219) & 72 / 219 & 33 & 147 / 219 & 67 \\ \text { Yes }(n=339) & 159 / 339 & 47 & 180 / 339 & 53\end{array}$

Results could be an obstacle to getting/keeping health insurance

$\begin{array}{lllll}\text { No }(n=281) & 107 / 281 & 38 & 174 / 281 & 62 \\ \text { Yes }(n-277) & 125 / 277 & 45 & 152 / 277 & 55\end{array}$

Health insurance coverage would be an obstacle to getting a genetic test

$\begin{array}{lllll}\text { No }(n=348) & 143 / 348 & 41 & 205 / 348 & 59 \\ \text { Yes }(n=210) & 88 / 210 & 42 & 122 / 210 & 58\end{array}$

Having a genetic test would cost too much money

$\begin{array}{lllll}\text { No }(n=389) & 167 / 389 & 43 & 222 / 389 & 57 \\ \text { Yes }(n=169) & 64 / 169 & 38 & 105 / 169 & 62\end{array}$

Would have a genetic test if it would cost $\$ 100$ or less ${ }^{\mathrm{a}}$

$\begin{array}{lllll}\text { No }(n=278) & 58 / 278 & 21 & 220 / 278 & 79 \\ \text { Yes }(n=280) & 190 / 280 & 68 & 90 / 280 & 32\end{array}$

Would have a genetic test if it would cost $\$ 1,000$ or less $^{\mathrm{a}}$

\begin{tabular}{lllll} 
No $(n=512)$ & $195 / 512$ & 38 & $317 / 512$ & 62 \\
Yes $(n=46)$ & $35 / 46$ & 76 & $11 / 46$ & 24 \\
\hline
\end{tabular}

Respondents answered the HBM components described as yes/no responses and their decision to engage in genetic testing based on the yes/no responses' classification based on each HBM item. Some HBM components had missing values and therefore the number of observations may vary across items.

${ }^{\text {a }}$ Statistically significant at the $95 \%$ level of confidence.

\section{Cues to Action}

Three items assessing the cues to action component were significant at the $95 \%$ level of confidence. Forty-six percent of the 344 respondents who said their physician or primary health care provider had discussed early detection of CRC with them intended to pursue genetic testing compared to $34 \%$ of the 214 respondents who had not received this 
feedback. Forty-four percent of the 500 respondents who said their physician would influence their decision reported they would pursue testing, compared to the $22 \%$ of the 58 respondents who did not regard their physician as influencing their decision. Forty-five percent of the 331 respondents who said another health professional would influence their decision reportedly would undergo genetic testing compared to $36 \%$ of the 227 respondents who did not perceive another health professional as being influential.

\section{Perceived Susceptibility}

Three items assessing the susceptibility component were significant at the $95 \%$ level of confidence. Fifty-seven percent of the 81 respondents who indicated they had a blood relative who had or currently has CRC also reported they would pursue genetic testing in the next six months compared to $39 \%$ of the 475 respondents who did not have an affected blood relative. Fifty-seven percent of the 23 respondents who perceived themselves as likely to contract $\mathrm{CRC}$ in their lifetime indicated an intention to be genetically tested in the next six months, compared to $36 \%$ of the 535 respondents who did not think view themselves as likely to contract CRC. Sixty-four percent of the 39 respondents who indicated their smoking habits put them at an increased their risk of developing CRC reported they would pursue genetic testing compared to $40 \%$ of the 513 respondents who indicated their smoking habits did not place them at an increased risk.

\section{Perceived Benefits}

Every item assessing the benefit component was significant at the $95 \%$ level of confidence. Fifty-three percent of the 389 respondents who indicated their family could receive useful health information from the results of their genetic test for CRC also reported they would be genetically tested in the next six months compared to only $14 \%$ of the 169 respondents who feel it would not be useful information for their family. Forty-six percent of the 411 respondents who indicted their family members could make better decision about their health also indicated they would be tested, compared to only $15 \%$ of the 147 respondents that did not think it would help family members make decisions. Fortyone percent of the 486 respondents who indicated the results from their genetic test would encourage a change in their lifestyle also reported they would be tested, compared to $17 \%$ of the 72 respondents who did not feel it would encourage a lifestyle change. Fifty-five percent of the 227 respondents who reported the genetic test for CRC would decrease their chances of requiring radical surgery also indicated they would pursue testing, compared to $32 \%$ of the 331 who did not think it would decrease their chance for surgery. Sixty-eight percent of the 254 respondents who indicated they would participate in a genetic test for CRC to satisfy their curiosity also reported they would pursue the test, compared to $20 \%$ of the 304 respondents who did not think the test would satisfy their curiosity.

\section{Perceived Barriers}

Three items assessing the barriers component were significant at the $95 \%$ level of confidence. Forty-seven percent of the 339 respondents who believed that a high risk classification for CRC through genetic testing would likely have a large financial impact on themselves or their family also reported they would pursue the test, compared to $33 \%$ of the 219 respondents who believed it would not have a large financial impact. Sixty-eight percent of the 280 respondents who said they would participate in a genetic test if their actual out of pocket cost was less than one-hundred dollars also said they would pursue genetic testing in the next six months, compared to $21 \%$ of the 278 respondents who would not participate in a genetic test costing less than one-hundred dollars. Seventy-six percent of the 46 respondents who said they would participate in a genetic test if their actual out of pocket cost was less than one-thousand dollars also indicated they would pursue testing in the next six months, compared to $38 \%$ of the 512 respondents who would not participate in genetic testing costing less than one-thousand dollars.

\section{Regression Analyses}

The survey data were analyzed using two different series of logistic regression analyses. One series of regression analyses was run using component specific items for each component of the HBM (cues to action, perceived susceptibility, perceived benefits and barriers) to identify the likelihood of respondents undergoing genetic testing in the next 6 months (Table 3). In short, the regressions were used to identify what component items were significantly related to testing while holding constant the influence of other items associated with that component. For example, the influence of a physician discussing early detection could be evaluated while holding constant the influence of other cue to action component factors such as prior knowledge, discussing CRC with a physician, etc. Therefore, a total of four separate regressions that included all of the component items for each component were conducted. These regressions allowed the researchers to measure the impact of each component separately.

The second regression analyses included the component items for all four HBM components. This was a more sophisticated analysis since each item could be examined 
Table 3 Logistic Regression Analyses Examining the Influence of Individual HBM Components (Cues to Action, Perceived Susceptibility, Benefits and Barriers) on the Likelihood to Undergo Genetic Testing in the Next 6 Months

\begin{tabular}{|c|c|c|c|}
\hline Characteristics & $\begin{array}{l}\text { Parameter } \\
\text { estimate }\end{array}$ & $\begin{array}{l}\text { Standard } \\
\text { error }\end{array}$ & $p$-value \\
\hline Intercept & -1.6462 & 0.3726 & $0.0000^{*}$ \\
\hline \multicolumn{4}{|l|}{ Cues to Action } \\
\hline Prior knowledge of genetic testing & 0.1798 & 0.2076 & 0.3864 \\
\hline Physician discussed genetic testing for CRC & 0.2702 & 0.3791 & 0.4761 \\
\hline Physician discussed early detection for CRC & 0.4209 & 0.1872 & $0.0246^{*}$ \\
\hline Read/heard about genetic testing in the media & 0.0041 & 0.3409 & 0.9904 \\
\hline A family member would influence decision to be genetically tested & -0.0495 & 0.1798 & 0.7831 \\
\hline A physician would influence decision to be genetically tested & 0.8054 & 0.3383 & $0.0173^{*}$ \\
\hline A health care professional would influence decision to be genetically tested & 0.2930 & 0.1872 & 0.1176 \\
\hline Cox and Snell R-squared & & & 0.0360 \\
\hline Intercept & -0.5842 & 0.1046 & $0.0000^{*}$ \\
\hline \multicolumn{4}{|l|}{ Perceived Susceptibility } \\
\hline Blood relative with $\mathrm{CRC}$ & 0.6317 & 0.2526 & $0.0124 *$ \\
\hline Likelihood of CRC in lifetime & 1.4312 & 0.5287 & $0.0068^{*}$ \\
\hline Nutritional habits & 0.0654 & 0.3638 & 0.8573 \\
\hline Exercise habits & 0.3827 & 0.3919 & 0.3289 \\
\hline Smoking habits & 0.9989 & 0.3544 & $0.0048^{*}$ \\
\hline Cox and Snell R-squared & & & 0.0500 \\
\hline Intercept & -3.0552 & 0.4155 & $0.0000^{*}$ \\
\hline \multicolumn{4}{|l|}{ Perceived Benefits } \\
\hline Beneficial information for family & 1.0892 & 0.3294 & $0.0009^{*}$ \\
\hline Family could make better decisions & 0.5208 & 0.3560 & 0.1435 \\
\hline Encourage lifestyle change & 0.4506 & 0.3976 & 0.2570 \\
\hline Decrease chance of surgery & 0.4063 & 0.2112 & $0.0544 *$ \\
\hline Satisfy curiosity & 1.8159 & 0.2073 & $0.0000^{*}$ \\
\hline Cox and Snell R-squared & & & 0.2830 \\
\hline Intercept & -1.5413 & 0.2041 & 0.0000 \\
\hline \multicolumn{4}{|l|}{ Perceived Barriers } \\
\hline Large impact on family & 0.3183 & 0.2143 & 0.1374 \\
\hline Obstacle to getting/keeping insurance & 0.3249 & 0.2133 & 0.1277 \\
\hline Concern for job security & -0.3160 & 0.2969 & 0.2872 \\
\hline Health insurance coverage would be an obstacle to genetic testing & 0.0289 & 0.2188 & 0.8948 \\
\hline Cost too much money & -0.4555 & 0.2286 & $0.0463 *$ \\
\hline Cost me less than $\$ 100$ & 1.6854 & 0.1987 & $0.0000^{*}$ \\
\hline Cost me less than $\$ 1,000$ & 1.2514 & 0.3937 & $0.0015^{*}$ \\
\hline Cox and Snell R-squared & & & 0.1910 \\
\hline
\end{tabular}

*Significant at $p \leq .05$

component were tested for significance at an alpha level of $p \leq .05$.

The HBM component of cues to action explained approximately $4 \%$ of the variance associated with genetic testing intention. The two items within the cues to action component that were significant included: physician discussed early detection for CRC with them, and a physician would influence a respondents' decision to be genetically tested.

Perceived susceptibility explained approximately $5 \%$ of the variance associated with genetic testing intention. The three items within the susceptibility component that were 
Table 4 Regression Analyses of the Influences of the Composite HBM Components on the Likelihood to be Genetically Tested for CRC in the Next Six Months
Characteristics

Parameter Standard $p$-value estimate error

Intercept

$-5.0919 \quad 1.1272$

0.0000

Cues to Action

Prior knowledge of genetic testing

Physician discussed genetic testing for CRC

Physician discussed early detection for CRC

$\mathrm{Read} /$ heard about genetic testing in the media

A family member would influence decision to be genetically tested

A physician would influence decision to be genetically tested

A health care professional would influence decision to be genetically tested

Perceived Susceptibility

Blood relative with $\mathrm{CRC}$

Likelihood of CRC in lifetime

Nutritional habits

Exercise habits

Smoking habits

Perceived Benefits

Beneficial information for family

Family could make better decisions

Encourage lifestyle change

Decrease chance of surgery

Satisfy curiosity

Perceived Barriers

Large impact on family

Obstacle to getting/keeping insurance

concern for job security

Health insurance coverage would be an obstacle to genetic testing

Cost too much money

Cost me less than $\$ 100$

Cost me less than $\$ 1,000$

Personal and Demographic

Health insurance status

Gender

Marital status

Number of dependents

Race

Age

Income

Education

Cox and Snell R-squared

$\begin{array}{rll}0.3403 & 0.2947 & 0.2482 \\ 0.3862 & 0.5102 & 0.4491 \\ 0.0648 & 0.2678 & 0.8087 \\ -0.4644 & 0.4710 & 0.3241 \\ 0.1611 & 0.2358 & 0.4945 \\ 0.2625 & 0.4369 & 0.5479 \\ 0.3005 & 0.2460 & 0.2220 \\ & & \\ 0.3990 & 0.3246 & 0.2189 \\ 1.0677 & 0.7249 & 0.1408 \\ -0.6137 & 0.4424 & 0.1654 \\ 0.6429 & 0.4952 & 0.1942 \\ 0.6363 & 0.4191 & 0.1289 \\ & & \\ 1.1182 & 0.3705 & 0.0025 * \\ 0.4159 & 0.3890 & 0.2850 \\ 0.4215 & 0.4381 & 0.3359 \\ 0.4295 & 0.2391 & 0.0725 \\ 1.5106 & 0.2467 & 0.0000 * \\ & & \\ 0.2022 & 0.2588 & 0.4346 \\ 0.1027 & 0.2569 & 0.6894 \\ -0.1945 & 0.3622 & 0.5913 \\ -0.0801 & 0.2630 & 0.7606 \\ -0.2291 & 0.2731 & 0.4017 \\ 0.8556 & 0.2501 & 0.0006 * \\ 0.7966 & 0.4583 & 0.0822 \\ & & \\ 0.6782 & 0.3532 & 0.0548 \\ 0.2596 & 0.2559 & 0.3103 \\ -0.1740 & 0.2709 & 0.5207 \\ 0.9912 & 0.2700 & 0.4129 \\ & 0.5550 & 0.0741 \\ 0.1960 & 0.0475 * \\ & 0.0048 & 0.4907 \\ 0.0123 & 0.3993 \\ & & 0.3570\end{array}$

*Significant $p \leq .05$

significant included: having a blood relative who has/had CRC, respondents' belief that they could contract CRC in their lifetime, and a belief that their smoking habits would increase their risk of contracting CRC.

Perceived benefits explained approximately $28 \%$ of the variance associated with intention to be tested for CRC in the next 6 months. The three items within the benefits component that were significant included: providing useful information for their family members, a decreased chance of surgery, and satisfying their own curiosity.

Perceived barriers explained approximately $19 \%$ of the variance associated with intention to be tested. Three items within the barrier component that were significant were financial, including if the test cost too much money, and if it costs less than $\$ 100$, or $\$ 1,000$; all were associated with increased intention to engage in genetic testing. 


\section{Four Component HBM Item Regression}

Table 4 displays the four component HBM regression analysis for all items related to each of the HBM components. Janz et al. (2002) recommended that when investigators use the HBM they include the individual items associated with each component, (e.g., perceived susceptibility, benefits, barriers, etc.). They made this recommendation because the analysis can provide more precise information that would allow practitioners to more accurately apply the findings to a given health enhancement effort. Based on this recommendation, the present researchers included each item associated with the four HBM components in the regression analysis rather than developing a composite score for each component.

The regression analysis showed that the composite HBM with all components accounted for approximately $36 \%$ of the variance for intention to engage in genetic testing for CRC in the next six months (Table 4). None of the cues to action or perceived susceptibility component items were found to be significant predictors of genetic testing intention. One demographic variable (age) was significant in this model. Older respondents were more likely to indicate an intention to pursue testing. Perceptions that test results would be beneficial to respondents' family and that they would satisfy the respondents' curiosity both significantly increased reported likelihood of pursuing testing. Finally, the barrier item of having costs less than $\$ 100$ significantly increased the likelihood that the respondents would pursue testing.

\section{Two-By-Two Tables}

The two-by-two tables shown in Table 5 were developed by first generating composite scores by summing responses to all the items within a given component. Next, a median split was conducted for each component to develop a high (values above the median) and low (values below the median) scores. Based on the high low classifications, calculations were made so that the percentage of respondents who intended to be tested for CRC in the next six months could be reported in the two-by-two tables. Since the regression analyses revealed that benefit items were the strongest predictor of testing intention, all components were compared to the benefit component.

The results support the strong association between the benefits component and the dependent variable of likelihood to be genetically tested in the next six months. The benefits and barriers comparisons revealed $44 \%$ of respondents intended to undergo genetic testing when barriers were low and benefits were high. However, when barriers and benefits were high, $63 \%$ of the respondents intended to be tested. This
Table 5 Percentage of Respondents Reporting Intention to be Tested by Perceived Benefits Perceived Barriers, Cues to Action and Perceived Susceptibility

\begin{tabular}{lll}
\hline & $\begin{array}{l}\text { Barriers } \\
\text { High }\end{array}$ & Low \\
Benefits & & \\
High & $63 \%$ & $44 \%$ \\
Low & $9 \%$ & $14 \%$ \\
& Cues to Action & \\
& High & Low \\
Benefits & & \\
High & $55 \%$ & $50 \%$ \\
Low & $14 \%$ & $9 \%$ \\
& Susceptibility & \\
Benefits & High & Low \\
High & $67 \%$ & $53 \%$ \\
Low & $50 \%$ & $12 \%$ \\
\hline
\end{tabular}

The two-by-two comparisons shown in this table were developed by first generating composite scores by summing the scores of all items within a given component. Next, a median split was conducted for each component to develop a high (values above the median) and low (values below the median) scores. Based on the high/low classifications, calculations were made so that the percentage of respondents who intended to be tested for CRC in the next six months could be reported in the two-by-two tables. Because the regression analyses revealed that benefit items were the strongest predictor of testing intention, All components were compared to the benefit component.

is the one pair that does not follow the expected pattern. Twoby-two tables can be an effective method for succinctly displaying complex concepts. However, this simplified depiction will occasionally produce inconsistent patterns. Nevertheless, the other seven pairs showed a consistent pattern. For instance, when benefits were low and barriers were high, $9 \%$ of the respondents intended to be tested. Similarly, when benefits were low and barriers were low, only $14 \%$ of the respondents intended to be tested. The dramatic and consistent pattern was also found for cues to action and susceptibility. For example, when cues and benefits were high $55 \%$ of the respondents intended to be tested. However when benefits were low and cues were low, only $9 \%$ reported an intention to be tested.

\section{Discussion}

The Health Belief Model has been used to predict health behavior over the past fifty years in urban, rural and frontier settings. This study examined the Health Belief Model's (HBM) efficacy for predicting intention to undergo genetic testing for the Colorectal Carcinoma (CRC) gene within a 
rural and frontier setting. Collectively, the analysis revealed that perceived benefits were the best indicators of intention to undergo genetic testing for CRC during the next 6 months. Other HBM component items were also found to be significant predictors such as perceived barriers, susceptibility and cues to action. Collectively the model explained approximately $36 \%$ of the variance in intention to pursue genetic testing. These preliminary findings have implications for genetic counselors and other health practitioners concerned with addressing the public health issue of genetic testing for CRC in a rural and frontier area.

For instance, the majority of the respondents (approximately $59 \%$ ) indicated that they intended to be genetically tested for CRC in the next 6 months. However, a sizable percentage $(41 \%)$ did not intend to pursue testing. In order for counselors and other health practitioners to better assist individuals to make appropriate decisions, it is necessary for practitioners to understand the factors that are most important in the decision making process. These factors would include those that encourage (curiosity) and dissuade (costs) participation.

Bunn et al. (2002) found that the HBM was a good predictor of urban dwelling adults' decision to undergo genetic testing for CRC. The researchers found that perceived barriers, perceived benefits and perceived susceptibility had the greatest influence on the likelihood to engage in genetic testing. Specifically, the respondents generally agreed that genetic testing for cancer risk would be a benefit to their families and fewer respondents reported barriers to testing, with the highest reported barrier being financial in nature.

The results of the present investigation are congruent with these findings of Bunn et al. (2002) for the components of barriers and benefits, but not for susceptibility. In short, susceptibility proved to not be an important predictor of the intention to be tested for CRC. Consistent with Bunn et al. (2002), the present findings revealed that perceptions of testing result as being beneficial to one's family was significant. The results from this investigation also showed that decreasing one's chance for surgery was an important factor in all analyses except the four component regression. To our knowledge, this is the first study to demonstrate that satisfying one's curiosity about his/her own predisposition is a significant and important predictor of screening intention.

The barrier of costs was a significant predictor of intention even though many of the respondents were willing to pay as much as $\$ 1,000$ to receive the testing procedure. In other studies not specific to CRC, researchers have found that cost and insurance coverage are important predictors of the likelihood to be genetically tested (Gwyn et al. 2003). The findings of this study provide additional support that costs are an important determinant for testing intention. However, there is a need to more precisely identify how much consumers will actually spend for genetic testing.

There was some support for the notion that one's physician could influence the respondent's intention to be tested. However, when all of the components of the HBM were entered into a single regression, the physician was no longer a significant cue to action. The results are not definitive and additional research is needed to clarify the relationship between testing intention and the physician as an important cue to action.

There was some support that circumstances (e.g., blood relative who has/had CRC) and behaviors (e.g., smoking habits related to perceptions of susceptibility) could influence the respondent's intention to be tested. However, when all of all components of the HBM were entered into a single regression, the susceptibility items were no longer a significant. Prior to this study, much of the genetic testing education has focused on client perceived susceptibility (Bunn et al. 2002; Helmes et al. 2000; Ho et al. 2003; U.S. Department of Energy Office of Science, Office of Biological and Environmental Research, \& Program 2004; U.S. Department of Health and Human Services and National Cancer Institute 2007). For example, education has focused on consumers' likelihood to contract CRC based on family history, and lifestyle such as diet, exercise or smoking habits. However, based on the present findings for a rural/frontier sample, it appears that these factors would not be the primary focus of an educational campaign.

One concern with the present analysis involves the wording of the lifestyle habits (i.e., nutrition, exercise and smoking). In these questions respondents were asked whether their exercise, nutrition and smoking habits influenced their risk for CRC. The assumption was that favorable habits reduced risk (e.g., non-smokers would have a lower risk). However, respondents were not asked about their actual exercise, nutritional and smoking habits. Having this information might have altered the results if respondents equated poor nutrition, sedentary lifestyles and smoking with decreased risk for health. These counterintuitive assumptions on the part of respondents are not likely, but it is an issue future researchers should address in subsequent studies.

\section{Conclusion}

Further research is needed to more definitively clarify the determinants of intention to be genetically tested for CRC and better guide counselors and health practitioners in their intervention efforts. Use of the HBM to guide future investigations is warranted in that the constructs derived from the model helped the present researchers identify 
specific items that were strong predictors of intention for genetic testing. In total, the model explained $36 \%$ of the variance. Specifically, this study showed that perceived barriers and benefits directly influenced the intention to be tested - especially the benefit of satisfying ones curiosity, obtaining beneficial information for one's family members, and appropriate pricing of the test. These findings have direct implications for designing educational strategies to improve decision-making concerning genetic testing for CRC risk in the rural and frontier population. Provision of information/education remains a vital tool for genetic counselors and other health care providers when addressing their patients'decisions to participate in genetic testing for any cancer risk. However, it also is important for practitioners to assess the cognitive, motivational and emotional factors that are important in a given patient's decision making process in order to help them make informed decisions. The findings from this preliminary study can be useful in this regard.

As more research is conducted to identify the factors that influence decision making, researchers and practitioners should thoroughly consider how this information may be best used. In this study the sampling was directed to the general population within rural and frontier settings. Should research efforts be directed solely to individuals who are at risk? If yes, how might the findings vary based on those populations? Also, how should the findings from these type of investigations be used? Specifically, should they be used to better inform individuals so that they can engage in reflection and introspection to make informed decisions? The answers to these questions are beyond the scope of this paper. However, they are critical as practitioners decide how to apply the findings from this study and from related research.

Acknowledgements This study was supported in part through a research development grant from the Department of Health and Human Development at Montana State University Bozeman.

\section{References}

American Cancer Society. (2006, February 14, 2006). Facts and figures 2006. from http://www.cancer.org/docroot/STT/stt 0.asp.

Babbie, E. (2002). The basics of social research. Belmont: Wadsworth Group.
Bosompra, K., Flynn, B. S., Ashikaga, T., Rairikar, C. J., Worden, J. K., \& Solomon, L. J. (2000). Likelihood of undergoing genetic testing for cancer risk: a population-based study. Preventive Medicine, 30, 155-166.

Bunn, J. K., Kwadwo, B., Takamaru, A., Flynn, B. S., \& Worden, F. (2002). Factors influencing intention to obtain a genetic test for colon cancer risk: a population-based study. Preventive Medicine, $34,567-577$.

Church, G. M. (2006). Genomes for ALL. Scientific American, 47-54. http://arep.med.harvard.edu/pdf/Church05s.pdf.

Dillman, D. A. (2000). Mail and internet surveys: The tailored design method (2nd ed.). New York: Wiley.

Frank, D., Swedmark, J., \& Grubbs, L. (2004). Colon cancer screening in African American women. The Association of Black Nursing Faculty, 15(4), 67-70.

Green, L. \& Kreuter, M. (1999). Health promotion planning: An educational and ecological approach (3rd ed.). Mountain View: Mayfield.

Gwyn, K., Vernon, S. W., \& Conoley, P. M. (2003). Intention to pursue genetic testing for breast cancer among women due for screening mammography. Cancer Epidemiology Biomarkers \& Prevention, 12, 96-102.

Hartman, K. A. (2002). Health belief model and it's application to mammography screening in a K-12 school district employee wellness program. Bozeman: Montana State University.

Helmes, A. W., Bowen, D. J., Bowden, R., \& Bengel, J. (2000). Predictors of participation in genetic research in a primary care physician network. Cancer Epidemiology, Biomarkers \& Prevention, 9, 1377-1379.

Ho, S. M., Ho, J. W., Chan, C. L., Kwan, K., \& Tsui, K. (2003). Decisional consideration of hereditary colon cancer genetic test results among Hong Kong Chinese adults. Cancer Epidemiology, Biomarkers \& Prevention, 12, 426-432.

Janz, N., Champion, V., \& Strecher, V. (2002). The health belief model. In K. Glanz, B. Rimer \& F. Lewis (Eds.), Health behavior and health education: Theory, research and practice. San Francisco: Jossey-Bass.

Keefer, C. M. (1999). Briding the gap between life insurer and consumer in the genetic testing era: the RF proposal. Indiana Law Journal, 74(4), 1375-1397.

Peterson, S. K. (2005). The role of the family in genetic testing: theoretical perspectives, current knowledge, and future directions. Health Education and Behavior, 32(5), 627-639.

Ramsey, S. D., Wilson, S., Spencer, A., Geidzinska, A., \& Newcomb, P. (2003). Attitudes towards genetics screening for predisposition to colon cancer among cancer patients, their relatives and members of the community. Community Genetics, 6, 29-36.

Strecher, V. J. \& Rosenstock, I. M. (1997). The health belief model. San Francisco: Jossey-Bass.

U.S. Department of Energy Office of Science, Office of Biological and Environmental Research, \& Program, H. G. (2004). Human Genome Project Information. In.

U.S. Department of Health and Human Services, \& National Cancer Institute. (2007). Understanding Genetic Testing: Access Excellence Resource Center. 